\title{
CAPOEIRA E FORMAÇÃO INICIAL EM EDUCAÇÃO FÍSICA: UM ESTUDO DE CASO
}

\author{
Paula Cristina da Costa Silva \\ Universidade Federal do Espírito Santo, Vitória, Espírito Santo, Brasil. \\ Jéssica Karina Silva Ferreira \\ Rede municipal de ensino de Viana-ES, Viana, Espírito Santo, Brasil. \\ Cássia Maria Hess \\ Universidade Estadual de Campinas, Limeira, Campinas, Brasil. \\ Eliana de Toledo \\ Universidade Estadual de Campinas, Limeira, Campinas, Brasil.
}

\begin{abstract}
Resumo
A Capoeira vem se destacando nos ambientes educativos, mas há poucas pesquisas sobre sua presença na formação inicial. O objetivo deste estudo foi o de identificar e analisar o impacto do ensino-aprendizado da Capoeira num curso de Licenciatura em EF, com maior foco nos conhecimentos apreendidos na formação inicial dos estudantes. A metodologia utilizada foi o estudo de caso. A análise de conteúdo foi feita com a triangulação dos dados, e a discussão se baseou nos conhecimentos mais relevantes abordados nas experiências que colaborariam com o futuro profissional e na verificação da relevância da Capoeira. Os dados indicaram que a maioria dos participantes reconheceu a importância da Capoeira como conteúdo, entretanto, foi apontada falta de autonomia dos estudantes com referência à sua formação inicial.
\end{abstract}

Palavras-chave: Formação profissional. Capoeira. Educação Física. Universidade.

\section{CAPOEIRA AND THE TRAINING IN PHYSICAL EDUCATION: A CASE STUDY}

\begin{abstract}
Capoeira has been prominent in educational environments, but there is little research on its incidence in the initial training. The purpose of this study is to identify the knowledge acquired in Capoeira teaching and learning and its importance in the initial training of the Physical Education undergraduates. The methodology used was the case study. The content analysis was done through the data triangulation, and the interpretation was based on the most relevant scholarly knowledge on the expected professional experiences and on the verification of the relevance of Capoeira. The data indicated that the majority of the participants recognized the importance of Capoeira as content, but they also pointed to a lack of autonomy of the students in their initial training.
\end{abstract}

Keywords: Professional training. Capoeira. Physical Education. University. 


\title{
CAPOEIRA Y FORMACIÓN INICIAL EN EDUCACIÓN FÍSICA: UN ESTUDIO DE CASO
}

\begin{abstract}
Resumen
La Capoeira está adquiriendo cierta relevancia en el contexto educativo, sin embargo, hay pocas investigaciones sobre la presencia de ese deporte enlaformación inicial. El objetivo de este estudio esidentificar y analizar el impacto de la enseñanza-aprendizaje de la Capoeiraen un curso de la carrera de Educación Física, con foco en los conocimientos asimilados en la formación inicial de los estudiantes. Se utilizó el estudio de caso como metodología. El análisis de contenido fue realizado mediante la triangulación de los datos. La discusión se fundamento en torno a los conocimientos más relevantes tratados en las experiencias de colaboración del futuro profesional y enla verificación de la importancia de la Capoeira. Los datos mostraron que la mayoría de los participantes reconocióla relevancia de la Capoeira como contenido, a pesar de eso, se identificófalta de autonomía del alumnado en relación con su formación inicial.
\end{abstract}

Palabras clave: Capacitación profesional. Capoeira. Educación física. Universidad.

\section{Introdução}

As pesquisas acerca da história da Capoeira ${ }^{1}$ no Brasil convergem para seu surgimento com o tráfico de escravos negros, porém, não sabemos qual a data precisa e nem o local onde sua manifestação se iniciou.

Entretanto, para Pires (1996; 2001) e Soares (2001), a Capoeira tornou-se uma manifestação presente no Rio de Janeiro, a partir do século XIX, fazendo parte da cultura urbana e marginalizada que incluía escravos, ex-escravos, imigrantes e trabalhadores. Foi amplamente perseguida nesse período por fomentar os ajuntamentos de escravos que poderiam possibilitar a organização de revoltas contra o sistema escravocrata.

Após a assinatura da Lei Áurea (em 1888), que libertou oficialmente os escravos (sem dar-lhes condições adequadas de inserção social), e a Proclamação da República (em 1889), a Capoeira teve sua inclusão no Código Penal da República, em 11 de outubro de 1890, como delito ou contravenção criminal (PIRES, 1996).

Vale mencionar que a Capoeira muitas vezes prestava um serviço ambíguo de interesse das maltas que dividiam a cidade do Rio de Janeiro, 2 ora favorável aos escravos e oprimidos, ora a favor do status quo.

De toda forma, é inegável que a Capoeira serviu como uma arma contra a opressão ao sistema escravocrata, entretanto, consideramos que sua maior vitória foi permanecer como uma manifestação da cultura corporal que até hoje é transmitida e perpetuada, seja no que ela representou na resistência dos negros contra a escravidão, seja na reflexão do legado da cultura africana para a sociedade brasileira.

A perseguição à Capoeira perdurou até o governo populista de Getúlio Vargas (década de 1930), quando ela foi legalizada e passou por um processo de reinvenção de suas tradições (REIS, 1997b). No início do século XX, a Capoeira sofreu influências advindas da Educação Física (EF), como a dos métodos ginásticos e do esporte (SILVA, 2002; FALCÃO, 2004b).

\footnotetext{
${ }^{1}$ A escrita da palavra Capoeira com "C" maiúsculo será para tratá-la como manifestação cultural, multifacetada, distinguindo-a de outras formas como pode ser grafada, por exemplo, "capoeiras”, que se trata de seus praticantes antes de sua liberalização na década de 1930.

2 Como no episódio de repressão dos soldados estrangeiros amotinados em 1828 (ver SOARES, 2001, p. 61). 
A Capoeira assumiu novas formas de se manifestar, expressas em duas principais modalidades: ${ }^{3}$ a Capoeira Angola e a Regional, ambas com mestres de capoeira baianos à frente de suas respectivas organizações (REIS, 1997b).

Atualmente, a Capoeira tem outras modalidades, como a Contemporânea, ${ }^{4}$ por exemplo, e vem sendo difundida em todo o mundo (REIS, 1997b; FALCÃO, 2004a). Em 26 de novembro de 2014, a Roda de Capoeira recebeu o título de Patrimônio Imaterial da Humanidade pela Unesco (BRASIL, 2007).

Concordamos com Soares et al. (2012), quando afirmam que a Capoeira é uma produção da cultura corporal, que pode ser considerada um tipo de linguagem, compondo um registro de saberes, sentidos e significados que permeiam a realidade complexa em que vivemos. Além disso, ela tem um caráter multifacetado, portanto, sua abordagem pode ocorrer em diversos ambientes. Pode ser considerada como uma dança, uma luta, um esporte e mesmo como uma filosofia de vida (MENDONÇA, 2013).

Nesse contexto, o ensino da Capoeira na universidade e nas escolas se justifica por ser uma produção da cultura corporal, assim como por sua riqueza e importância histórica, além de seu significado como uma forma de resistência cultural. No entanto, para que esse conteúdo seja democratizado, é fundamental um trabalho de sensibilização dos futuros professores que cursam as licenciaturas, seja em EF, Artes, História, Letras, Geografia, seja em outro campo do conhecimento correlato, proporcionando-lhes a oportunidade de conhecer, aprender e refletir sobre ela durante sua formação.

Embora esse tema se apresente como relevante, encontramos somente quatro obras específicas sobre a Capoeira na formação inicial em EF: a de Gonçalves (1997), as de Falcão (2004a, 2004b) e a de Santos e Palhares (2010). Esses últimos autores apontam a importância de a Capoeira ser considerada parte do acervo de conhecimentos relativos às práticas corporais e, como tal, deve ser estudada e tratada no momento de formação inicial do professor. Eles recomendam que sua abordagem, no âmbito escolar, leve em conta os preceitos indicados pelos Parâmetros Curriculares Nacionais (PCN) (BRASIL, 1997), alinhados em três dimensões: conceitual, procedimental e atitudinal.

No que tange à legislação brasileira, no âmbito do sistema de ensino básico, além das indicações dos PCN, há as Orientações Curriculares para o Ensino Médio (BRASIL, 2006), documento no qual a disciplina EF se encontra na área de Linguagens e aponta a Capoeira como um conteúdo a ser trabalhado como uma prática corporal de origem afro-brasileira, que deve ser tratada para além da sua esportivização.

Muitos outros documentos curriculares oficiais vêm sendo elaborados pelas políticas públicas educacionais no Brasil, desde a última década, como mais recentemente a Base Nacional Comum Curricular (BNCC) e as propostas curriculares estaduais e municipais. Documentos estes que vêm contemplando a Capoeira como um conhecimento a ser ensinado nas aulas de EF. A análise das propostas para o ensino da Capoeira contidas nesses documentos (como tema, conteúdo, metodologias utilizadas, entre outras questões), e até mesmo os motivos que impulsionaram sua presença neles, certamente merecem estudo e se constituem o foco de uma próxima publicação.

A priori destacamos que esses documentos, como a BNCC (BRASIL, 2017) tem:

\footnotetext{
${ }^{3}$ Usamos no texto o termo modalidades, pois, com sua reinvenção pelos mestres baianos, a Capoeira passa a se aproximar do fenômeno esportivo. Um dos ícones da Capoeira, Mestre Bimba, chamava-a de Luta Regional Baiana, e Mestre Pastinha, outro representante importante da Capoeira Angola, organizava suas aulas no Centro Esportivo de Capoeira Angola. Para maiores informações, consultar Pires (2001).

${ }^{4}$ De acordo com Falcão (2004a, p. 60), a Capoeira Contemporânea é um “[...] complexo processo de criação de símbolos, de imagens, de memórias, de narrativas, de mitos, seguramente contraditórios, fragmentados e inacabados", tendo seus significados construídos pelos diferentes grupos a partir de seus interesses cotidianos e é marcada pelo seu caráter de multiciplidade.
} 
caráter normativo que define o conjunto orgânico e progressivo de 'aprendizagens essenciais' que todos os alunos devem desenvolver ao longo das etapas e modalidades da Educação Básica, de modo a que tenham assegurados seus direitos de aprendizagem e desenvolvimento, em conformidade com o que preceitua o Plano Nacional de Educação (PNE). Este documento normativo aplica-se exclusivamente à educação escolar, tal como a define o $\S 1^{\circ}$ do Artigo $1^{\circ}$ da Lei de Diretrizes e Bases da Educação Nacional (LDB, Lei $n^{\circ}$ 9.394/1996), e está orientado pelos princípios éticos, políticos e estéticos que visam à formação humana integral e à construção de uma sociedade justa, democrática e inclusiva, como fundamentado nas Diretrizes Curriculares Nacionais da Educação Básica (DCN). (BRASIL, 2017, p. 7).

Portanto, presume-se que esses conhecimentos da Capoeira propostos nos documentos oficiais que abrangem a área da Educação Física terão que estar contemplados na matriz curricular na formação inicial dos futuros professores, contudo, de maneira crítica, e não somente conteudista.

No caso da BNCC, por exemplo, propõe-se o ensino da Capoeira como um dos conteúdos presentes na unidade temática "Lutas do contexto comunitário e regional", que deve ser ministrado do $3^{\circ}$ ao $5^{\circ}$ anos do ensino fundamental. Nesse ciclo, são recomendadas a experimentação e a fruição das diferentes lutas no contexto comunitário e regional, o planejamento e a utilização de suas estratégias básicas, o reconhecimento de suas características e a diferenciação das lutas de "brigas" e das demais práticas corporais (BRASIL, 2017). Nesse mesmo documento, recomenda-se a abordagem das "Lutas do Brasil", do $6^{\circ}$ ao $9^{\circ}$ anos do ensino fundamental, acrescentando-se, além do recomendado no ciclo anterior, a experimentação e a fruição das diferentes lutas brasileiras, a identificação dos códigos, rituais, elementos técnico-táticos, indumentárias, materiais, instalações e instituições das lutas do Brasil. Além disso, ainda propõe "[...] problematizar preconceitos e estereótipos de gênero, sociais e étnico-raciais relacionados ao universo das lutas e demais práticas corporais e estabelecer acordos objetivando a construção de interações referenciadas na solidariedade, na justiça, na equidade e no respeito" (BRASIL, 2017, p. 193).

De acordo com Soares et al. (2012) a Capoeira é um conteúdo amplo que, embora tenha também um caráter de luta, deve ser tratada como uma manifestação cultural buscando realizar seu estudo sem desencarná-la de sua historicidade e do movimento cultural e político que a gerou. Nesse sentido, esse entendimento não está em sintonia com o que é apresentado nas BNCC e, assim, torna-se necessário reforçar a formação dos futuros professores para que tenham acesso a esse conhecimento e possam apropriar-se dele e, com autonomia, ressignificá-lo na escola, de acordo com suas condições sociais de produção. Vale mencionar ainda que os documentos oficiais, que preconizam os conteúdos a serem tratados nas aulas, podem dar um respaldo para os professores constituírem um corpo de conhecimento a ser estudado, entretanto, cabe ao docente realizar sua abordagem de forma crítica.

Para além dos documentos oficiais, em nível nacional, há ainda os de nível estadual, ${ }^{5}$ como a Proposta Curricular de São Paulo, de 2008, que inclui a Capoeira como uma manifestação da cultura de movimento, que abarca "[...] ao mesmo tempo luta, jogo e dança, tendo sido objeto de um processo de esportivização" (SÃO PAULO, 2008, p. 44). E a da Bahia, na qual há as Orientações Curriculares para o Ensino Fundamental (BAHIA, 2013) e para o Ensino Médio (BAHIA, 2015), que tratam, respectivamente, a Capoeira como um tema de lutas e como uma manifestação cultural multifacetada.

\footnotetext{
${ }^{5}$ Além das mencionadas, ainda há as Diretrizes Curriculares de outros estados brasileiros que também tratam da Capoeira ora como luta, ora como manifestação cultural. Não iremos aprofundar o debate, pois consideramos que os dados apontados são suficientes para a discussão neste artigo.
} 
Embora os dados levantados apontem para uma convergência de um visível crescimento da inserção da Capoeira nos currículos da Educação Básica, nos documentos oficiais públicos (curriculares) e nas produções acadêmicas, constatamos que o seu estudo na formação inicial em EF parece ainda estar fragilizado e precisando ser mais adensado.

Nesse contexto, esta investigação foi desenvolvida tendo como objetivo identificar e analisar o impacto do ensino-aprendizado da Capoeira num curso de Licenciatura em EF, com maior foco nos conhecimentos apreendidos na formação inicial dos estudantes.

\section{Aspectos metodológicos}

Esta pesquisa foi desenvolvida numa Instituição de Ensino Superior (IES), em Vitória - ES, na qual as aulas de Capoeira foram ministradas na disciplina Oficina de Docência em Capoeira, ${ }^{6}$ no primeiro semestre de 2013, com 15 encontros ocorridos uma vez por semana, com duração de duas horas cada um.

A metodologia adotada para a pesquisa foi qualitativa, exploratória, com ênfase no estudo de caso. A escolha desse método ocorreu por corroborarmos os estudos de Molina (2010, p. 102) no que se refere ao objetivo a ser atingido, que é "[...] tentar responder a problemas e perguntas que se formatam em 'comos' e/ou 'porquês' e que se interessam por acontecimentos contemporâneos dos quais obtemos poucas informações sistematizadas".

Ainda de acordo com a autora, o estudo de caso caracteriza-se por ter um interesse particular em determinada situação, podendo ser generalizado nos demais contextos educativos similares. É indutivo, descritivo, heurístico, possibilitando ampliar a compreensão e a experiência sobre o tema (MOLINA, 2010).

O levantamento bibliográfico foi realizado nas bases de dados do Sistema de Bibliotecas da Universidade Federal do Espírito Santo, tendo como palavras-chave: ensinoaprendizado da Capoeira; Capoeira na formação inicial de professores de Educação Física; formação docente em Educação Física, e Capoeira na universidade.

Os instrumentos utilizados na imersão em campo foram:

a) observação na perspectiva de participante-observador (NEGRINE, 2010), com as informações registradas em um diário de campo, seguindo as estratégias de registro não estruturado e de participação ativa. Foram acompanhados os acadêmicos de EF (30 alunos), que faziam a disciplina Oficina de Docência em Capoeira, do curso de Licenciatura em EF;

b) questionário fechado, ${ }^{7}$ que continha nove perguntas dissertativas, às quais os participantes responderam na última aula do semestre. As três questões iniciais diziam respeito aos dados pessoais (letras iniciais do nome, idade e período cursado);

c) documentos produzidos pelos alunos, com base nos trabalhos finais dos participantes da referida disciplina, que consistiam na produção de um plano de ensino, em grupos, que compreendessem, no mínimo, oito aulas de iniciação à prática da Capoeira na escola, em diferentes níveis (infantil, fundamental e

\footnotetext{
${ }^{6}$ As oficinas são disciplinas optativas da IES na qual fizemos esta investigação. Elas são de 30 horas e têm por objetivo oportunizar aos estudantes uma experiência significativa, capacitando-os para o exercício profissional na Educação Básica, por meio de experiências teórico-práticas materializadas sobre a realidade concreta, desenvolvendo um aprendizado crítico sobre o conteúdo abordado, por meio das experiências de movimento, como a dança, a ginástica, os esportes e a Capoeira, entre outras.

${ }^{7}$ O questionário baseou-se no utilizado na investigação de Silva (2009).
} 
médio). Dever-se-ia imaginar uma escola fictícia, ou seja, com características físicas, sociais e estruturais de acordo com o que cada grupo desejasse. Essa atividade foi proposta previamente, com um mês de antecedência ao final do semestre, para que os estudantes tivessem tempo de refletir sobre o que vivenciaram e o que poderiam sugerir para seus futuros alunos. Esses planos, por sua vez, foram analisados, a fim de constatar a apreensão do que foi tratado nas aulas com relação ao conhecimento e ao reflexo no processo de formação.

A interpretação das respostas (dados) obtidas pelos questionários foi realizada com base na análise de conteúdo de Bardin (2011), que considera como unidade de contexto (UC) a resposta completa em cada uma das questões abertas e, como unidades de registro, o destacamento de expressões mais significativas para a construção das respostas.

Identificadas as unidades de contexto, e as respectivas unidades de registro, são estabelecidas categorias, a partir do agrupamento de unidades de registro que contenham similaridade entre elas, com temas centrais comuns e que, por sua vez, nomeiam essas categorias.

A partir dos resultados obtidos na análise dos questionários, realizamos um cruzamento desses dados com as demais informações coletadas na observação participante e nos trabalhos finais, proporcionando um vasto material para a discussão.

Esta pesquisa obteve aprovação do Comitê de Ética de Pesquisa, com o Parecer consubstanciado $\mathrm{n}^{\mathrm{o}} 373.555 / 2013$.

\section{As aulas de capoeira}

Com a modificação, em 2006, do currículo de Licenciatura em EF, na IES na qual desenvolvemos esta pesquisa, o conteúdo Capoeira passou a ser ensinado em duas disciplinas optativas: Oficina de Docência em Capoeira e Atividades Interativas de Formação (Atif) - EF e Linguagens I. $^{8}$

A Oficina de Docência em Capoeira tem como ementa tratar do "Conhecimento relativo à Capoeira e experiência docente no trato pedagógico desse conteúdo de ensino" (UFES, 2014, p. 53)

No início das aulas, segundo o Plano da Disciplina (PD), levamos em consideração o pressuposto da reflexão pedagógica diagnóstica de ensino da cultura corporal (SOARES et al., 2012), de maneira que buscamos identificar os conhecimentos que os alunos tinham sobre essa manifestação.

A maioria dos estudantes disse não ter vivido nenhuma experiência anterior com relação à Capoeira. Diante do resultado, a docente optou em ter o cuidado de explorar metodologias e estratégias diversificadas, como: apresentação de vídeos, brincadeiras, aulas historiadas e teatralizadas, sempre numa perspectiva lúdica. Para eles, o ensino da Capoeira na escola deveria ser uma prática atraente, criativa e diversificada, podendo ser incorporada em todos os níveis de escolarização.

Nas aulas, os aspectos históricos e gestuais foram explorados conjuntamente, baseando-se nos trabalhos de Rocha (1990), Silva (1995), Reis (1997a), Araújo (2004) e Silva (2009), que serviram de fundamento para a elaboração do PD. Por meio de aulas teatralizadas, estimulava-se a participação dos alunos, narrando histórias sobre o percurso da Capoeira e

\footnotetext{
${ }^{8}$ As disciplinas denominadas Atifs têm como objetivo propiciar aos graduandos vivências relativas ao campo de trabalho, aumentando sua experiência advinda das práticas de ensino das manifestações culturais que compõem o rol de conhecimentos da área. Estas, apesar de optativas quanto à temática tratada, constituem carga horária obrigatória de 240 horas para a graduação em Licenciatura, no curso de EF do local onde ocorreu a pesquisa.
} 
realizando dinâmicas e brincadeiras que remetiam ao que era narrado. ${ }^{9}$ Com isso, os discentes, aos poucos, foram percebendo que é possível ensiná-la, dialeticamente, articulando os saberes que envolvem a sua história e adaptando todo o conteúdo característico dessa manifestação para a realidade.

Coerentemente com o PD, também foram ensinados os gestos do jogo da Capoeira, como ginga, cocorinha, aú, queda de rim, esquiva, bananeira, rabo de arraia, meia-lua de frente, meia-lua de costas, negativa, finta, entre outros, ${ }^{10}$ mesclando as estratégias de ensino de acordo com a aula. A escolha desses gestos deu-se pelo fato de eles serem de menor complexidade para o ensino-aprendizado e por estarem presentes tanto na Capoeira Angola como na Regional e na Contemporânea.

No decorrer da disciplina, a progressão dos estudantes foi visivelmente significativa, de modo que, aos poucos, o aprendizado histórico, gestual e musical, como também o seu repertório e o entendimento do que é o jogo de Capoeira foram se ampliando. Essa constatação foi visível na medida em que os discentes começaram a interagir de forma mais deliberada nos exercícios propostos pelo PD, na participação das "minirrodas" "11 de Capoeira, na discussão sobre o significado das brincadeiras propostas e no exercício das cantigas de Capoeira.

É importante dizer que as brincadeiras se apresentaram como uma importante estratégia pedagógica, pois serviram de base para a apropriação de novos conceitos. Foi por meio delas que ocorreu a adaptação de conteúdos (transposição didática), favorecendo a articulação dos diferentes tipos de aprendizado (gestual e cognitivo), de modo que os alunos aprendiam brincando, apreendendo valores, como o respeito ao próximo.

A Capoeira, ao adentrar a escola, passa a incorporar sentidos, códigos e valores diferentes dos praticados fora dela. Diante disso, para se jogar bem, é necessário mais do que conhecer seus movimentos; é fundamental compreender o sentido e as possibilidades do seu jogo, conhecer a sua história, seus fundamentos e rituais, o universo que a gerou e que compõe o significado desses movimentos, ou seja, entender o funcionamento de sua parte rítmica e musical, vivenciar seu universo e, assim, aprender a jogar (SILVA, 2009).

Além da parte gestual, conforme previsto no PD, foi ensinada a musicalidade da Capoeira, não sendo possível dissociá-la do jogo, ou seja, a música é que dita o ritmo e a energia da roda. Nesse sentido, estimulamos os estudantes a perceberem a riqueza e a diversidade do repertório musical que compõe a sua prática.

Também foram organizadas rodas de Capoeira, assim como foram ensinados os rituais e os fundamentos que dela fazem parte. Nessas ocasiões, com o auxílio da professora, os alunos tocaram os instrumentos musicais, jogaram e observaram, atentos ao que estava acontecendo, além de responderem ao coro.

Alguns alunos se sentiram inseguros ao jogar na roda. Diziam que as aulas são distintas daquilo que se vivenciava na roda. Muitos estavam envergonhados e não queriam jogar, porém, foram encorajados pela docente que relembrou os gestos por eles aprendidos no decorrer das aulas, mostrando como poderiam ser encadeados. Ela também jogou com muitos alunos que estavam encabulados e eles puderam vivenciar os sentimentos que envolvem a roda de Capoeira.

\footnotetext{
${ }^{9}$ No texto de Autoras (2015), são descritas algumas atividades desenvolvidas no PD. Essa publicação foi realizada após esta pesquisa, como resultado das experiências das autoras ministrando aulas de Capoeira na universidade e em outros espaços sociais.

${ }^{10}$ Para saber mais sobre a nomenclatura e a execução dos golpes, contragolpes, ataques e defesas da Capoeira, sugerimos a leitura de CAPOEIRA, Nestor. Capoeira: os fundamentos da malícia. Rio de Janeiro: Record, 1992.

${ }^{11}$ A minirroda de Capoeira é um exercício no qual dois estudantes jogam entre si livremente, ao som de cantigas de Capoeira, e, ao sinal da professora, trocam de parceiro, buscando um outro colega que ainda não tenha jogado.
} 
As aulas da disciplina encerraram-se com a apresentação dos planos de ensino produzidos pelos grupos.

\section{Análise dos questionários}

Ao final do semestre letivo, os alunos ${ }^{12}$ responderam ao questionário como uma forma de analisar parcialmente o que apreenderam durante as aulas. Selecionamos somente três questões que fazem relação direta com os objetivos propostos neste artigo. Essa escolha deu-se com base nas categorias emergentes delineadas pelas investigadoras no processo de análise dos dados deste estudo de caso (MOLINA, 2010).

Com referência aos dados etários, a maioria dos participantes tinha entre 20 e 23 anos. Dentre eles, 14 encontravam-se no $5^{\circ}$ e $7^{\circ}$ períodos.

A primeira questão analisada foi: Do que você estudou na oficina de Capoeira, quais os conhecimentos que considerou mais relevantes? (Tabela 1).

\footnotetext{
${ }^{12}$ Os alunos participantes serão identificados por números para manter sua identidade preservada.
} 
Tabela 1 - Unidades de contexto das respostas da questão

\section{UNIDADES DE CONTEXTO (UC)}

ALUNOS

FREQUÊNCIA

\begin{tabular}{lll}
\hline 1. Contexto da capoeira & $\mathrm{A} 4, \mathrm{~A} 9, \mathrm{~A} 17, \mathrm{~A} 18$ & 4 \\
\hline 2. Contextualização do negro no Brasil & $\mathrm{A} 17$ & 1 \\
\hline 3. Brincadeiras sobre a história da Capoeira & $\mathrm{A} 1, \mathrm{~A} 3, \mathrm{~A} 5, \mathrm{~A} 8, \mathrm{~A} 21$ & 5 \\
\hline 4. Canto & & \\
\hline 5. Capoeira angola & $\mathrm{A} 15$ & 1 \\
\hline $\begin{array}{l}\text { 6. Atividades lúdicas introduzindo a história da } \\
\text { Capoeira }\end{array}$ & $\mathrm{A} 1$ & 1 \\
\hline
\end{tabular}

\begin{tabular}{lll}
\hline 7. Aprendizado musical & A2, A16
\end{tabular}

\begin{tabular}{lll}
\hline 8. Músicas & $\mathrm{A} 6, \mathrm{~A} 14, \mathrm{~A} 15$ & 3 \\
\hline 9.Aprender a tocar os instrumentos & $\mathrm{A} 3, \mathrm{~A} 20$ & 2 \\
\hline 10. Instrumentos da Capoeira & $\mathrm{A} 13, \mathrm{~A} 20$ & 2 \\
\hline 11. História da Capoeira & $\mathrm{A} 2, \mathrm{~A} 4, \mathrm{~A} 5, \mathrm{~A} 6, \mathrm{~A} 9, \mathrm{~A} 10, \mathrm{~A} 11$, & 14 \\
& $\mathrm{~A} 12, \mathrm{~A} 14, \mathrm{~A} 15, \mathrm{~A} 16, \mathrm{~A} 17, \mathrm{~A} 19$, & \\
& $\mathrm{A} 20$ &
\end{tabular}

\begin{tabular}{lll}
\hline 12. Personagens & A11 & 1 \\
\hline 13. Apresentar ludicamente a Capoeira na escola & A6 & 1
\end{tabular}

\begin{tabular}{lll}
\hline 14. Brincadeiras & A7 & 1 \\
\hline 15. Uma nova maneira de trabalhar na escola & A20 & 1 \\
\hline 16. Vivência & A8 & 1 \\
\hline 17. Todos & A8, A9, A16 & 3 \\
\hline 18. Movimentos da Capoeira & A9, A10, A14, A15, A16, A21 & 6 \\
\hline 19. Surgimento na nossa cultura & A13 & 2 \\
\hline 20. Cultura da Capoeira & A19, A13 & 2 \\
\hline 21. Prática da Capoeira & A12, A13 & 1 \\
\hline 22. Acrobacias & A15 & 1 \\
\hline 23. Valores & A19 & 1 \\
\hline 24. Lendas & A19 & 1 \\
\hline $\begin{array}{l}\text { 25. Aprender um conteúdo que eu nunca tinha } \\
\text { vivenciado }\end{array}$ & A20 & 1 \\
\hline
\end{tabular}

Fonte: Elaborada pelas autoras, 2017. 
Tabela 2 - Categorias da questão 1 e suas respectivas unidades de contexto (UC)

CATEGORIAS UC TREQUENCIA

\begin{tabular}{lcc}
\hline $\begin{array}{l}\text { 1. Conhecimentos ligados à contextualização } \\
\text { histórica da Capoeira }\end{array}$ & $1,2,3,6,11,12,24$ & 27 \\
\hline $\begin{array}{l}\text { 2.Conhecimentos ligados ao se movimentar na } \\
\text { Capoeira }\end{array}$ & $14,16,18,21,22$ & 11 \\
\hline 3. Conhecimentos da musicalidade da Capoeira & $4,7,8,9,10$ & 10 \\
\hline 4. Conhecimentos culturais da Capoeira & 19,20 & 4 \\
\hline 5.Conhecimento de um conteúdo novo & 15,25 & 2 \\
\hline 6. Conhecimentos dos valores da Capoeira & 23 & 1 \\
\hline 7. Conhecimento da Capoeira Angola & 5 & 1 \\
\hline $\begin{array}{l}\text { 8. Conhecimento lúdico para ensinar a Capoeira } \\
\text { na escola }\end{array}$ & 13 & 1 \\
\hline 9. Todos & 17 & 3 \\
\hline
\end{tabular}

Fonte: Elaborada pelas autoras, 2017.

Dentre as Unidades de Contexto (UC) identificadas, as que mais se destacaram foram os conhecimentos ligados à contextualização histórica e ao "movimentar-se" da Capoeira. Isso provavelmente porque a maioria das aulas foi historiada ou composta por estratégias didáticas que tratavam da história da Capoeira, aliando-a ao ensino dos seus gestos. Podemos citar, por exemplo, a brincadeira de pegador, na qual a maioria dos estudantes eram os escravos fugidos e dois ou três deles, o capitão-do-mato. Assim que um dos "capitães-domato" tocava um dos "escravos fugidos", este deveria ficar agachado (posição da cocorinha, que é um gesto da Capoeira) e poderia voltar à brincadeira quando um outro "escravo fugido" passasse a perna por cima dele (como no golpe da meia-lua de frente). Antes do início da brincadeira, era realizada uma conversa sobre o conteúdo, abordando os elementos históricos e também os gestos corporais a serem aprendidos.

Esse conteúdo e as estratégias destacadas pelos estudantes vão ao encontro dos pressupostos apontados por Soares et al. (2012) e ao que é indicado pelas Orientações Curriculares para o Ensino Fundamental (BAHIA, 2013) e Médio da Bahia (BAHIA, 2015), que tratam da importância da contextualização histórica da Capoeira. Consequentemente, por meio desse tipo de abordagem, situa-se a história social dos negros no Brasil, que abarca o que é preconizado pela Lei $\mathrm{n}^{\circ} 10.639$, de 9 de janeiro de 2003, que inclui, no currículo oficial da Rede de Ensino, a obrigatoriedade da temática "História e Cultura Afro-Brasileira" (BRASIL, 2003).

Esse dado foi apontado pelo Aluno 17 e é também mencionado nas Orientações Curriculares para o Ensino Médio (BRASIL, 2006): “A Capoeira, guardiã do jogo, da brincadeira, do faz-de-conta que luta, mas joga com o outro, que simula um golpe e tira o outro para dançar, e que tem uma vinculação étnico e racial com o percurso e o lugar da negritude em nosso país [...]" (BRASIL, 2006, p. 231).

Essa perspectiva de ensino-aprendizado busca dar sentido e significado à temática estudada, tanto para situar o estudante que nessa situação ainda não havia tido contato com a Capoeira como para demonstrar a importância de se adotar estratégias de ensino que também ofereçam a oportunidade de conhecer para além dos gestos corporais ou das regras do jogo.

Com relação à categoria 3 (Conhecimentos da Musicalidade da Capoeira), que aponta a relevância do ensino da musicalidade, vale mencionar que muitos alunos expressaram, 
durante as vivências e nas apresentações dos planos de aula, dificuldades em seu aprendizado, alegando que o tempo destinado a esse tema na disciplina era muito pouco.

Concordamos com essa constatação e a complementamos, afirmando que a formação musical não tem sido valorizada no ensino formal e, também, fora desse contexto, pois não é um aprendizado escolhido pelos pais, porque tem um custo alto para a maioria das famílias brasileiras. Este é um dentre outros motivos para o seu "não ensino".

No que concerne ao ambiente acadêmico, cabe a reflexão acerca da presença da disciplina Rítmica e suas formas de desenvolvimento, como essencial para a formação do professor de EF, dado que muitas brincadeiras, jogos, modalidades esportivas, ginástica, Capoeira e outras manifestações que dialogam com a EF, como a dança e o circo, abordam os aspectos rítmicos. Embora esse aspecto seja valorizado pelos PCN (BRASIL, 1997) e outros documentos legais, cabe uma discussão acerca de sua presença tanto no ambiente escolar, dentro e fora das disciplinas de EF, como também na formação de professores.

Seria recomendável, no caso do ensino-aprendizado da Capoeira, a complementação desse processo por meio de vivências em grupos de Capoeira, tomando-se o devido cuidado em buscar referências sobre o grupo escolhido. Muitas vezes, conhecer o ambiente das aulas e frequentar as rodas promovidas pelo grupo eleito é uma maneira de observar se os participantes respeitam as tradições e se preocupam com a integridade física de seus praticantes. Nesse ponto, vale lembrar que uma das categorias apontadas é a importância dos valores no ensino-aprendizado da Capoeira. De acordo com a fala do Aluno 19, são "[...] os valores que são passados a quem vê e joga, onde se nota o respeito muito grande da roda, à cultura de Capoeira".

Assim, deve-se considerar também a importância dos mestres de Capoeira, que são os detentores desse conhecimento e que há anos vêm passando seu legado. Não podemos negar o valor deles na transmissão dessa tradição, como afirmam Santos e Palhares (2010, p. 3): "Há muitas maneiras de ensinar e os mestres de capoeira, apesar de não possuírem diplomas ou licença para lecionar em universidades ou outras instituições, são notórios na arte de ensinar a capoeira [...]". Para além disso, sua importância para as propostas de experiências, estórias e reflexões sobre a Capoeira.

Sobre a segunda questão analisada - Você pensa que essa experiência ajuda/ajudará durante as suas aulas? Como? -, todos os alunos consideraram a experiência positiva. Desse modo, nos restringiremos a analisar as UCs que se reportam ao esclarecimento de como essa vivência poderá colaborar durante as aulas a serem ministradas (Tabelas 3 e 4). 
Tabela 3 - Unidades de contexto das respostas da questão 2

\begin{tabular}{|c|c|c|}
\hline UNIDADES DE CONTEXTO & ALUNOS & FREQUÉNCLA \\
\hline 1. Conhecimentos sobre Capoeira Angola & A1 & 1 \\
\hline 2. Procedimentos de Plano de Ensino & A2 & 1 \\
\hline 3. Variação para ensinar Capoeira & $\mathrm{A} 3, \mathrm{~A} 8$ & 2 \\
\hline 4. Aquisişão de experiência para ministrar as aulas & A4 & 1 \\
\hline 5. Capoeira como conteúdo nas aulas & A5, A12 & 2 \\
\hline 6. Forma de inserção social & A6 & 1 \\
\hline $\begin{array}{l}\text { 7. Um processo metodológico que pode ser adaptado } \\
\text { dependendo da série a ser traballhada }\end{array}$ & A7 & 1 \\
\hline $\begin{array}{l}\text { 8. Todo conhecimento adquirido sendo transformado de } \\
\text { acordo com a faixa etária e apresentado na aula }\end{array}$ & A9 & 1 \\
\hline $\begin{array}{l}\text { 9. História e movimentos básicos que poderão nos ajudar em } \\
\text { aulas iniciais de capoeira }\end{array}$ & $\mathrm{A} 13$ & 1 \\
\hline 10. Teria que buscar mais materiais e bibliografias & $\mathrm{A} 10$ & 1 \\
\hline 11. Garantir consistência no contexto & A11 & 1 \\
\hline 12. Transmissão do conhecimento & A14 & 1 \\
\hline 13. Utilizou conceitos tratados nas aulas no próprio estágio & A15 & 1 \\
\hline 14. Como trabalhar na escola & $\mathrm{A} 16, \mathrm{~A} 17$ & 2 \\
\hline $\begin{array}{l}\text { 15. Por aprender a listória da Capoeira, tocar instrumentos } \\
\text { e técnicas }\end{array}$ & A18 & 1 \\
\hline $\begin{array}{l}\text { 16. Cada passo de cada aula, as avaliaçōes e como lidar com } \\
\text { as dificuldades com questôes religiosas }\end{array}$ & A 19 & 1 \\
\hline 17. Desenvolvimento da aula & A20 & 1 \\
\hline 18. Vivência prática da capoeira & A21 & 1 \\
\hline
\end{tabular}

Fonte: Elaborada pelas autoras, 2017.

Tabela 4 - Categorias das respostas da questão 2 e suas respectivas unidades de contexto

\begin{tabular}{llll}
\hline \multicolumn{1}{c}{ CATEGORIAS } & \multicolumn{1}{c}{ UC } & FREQUÊNCIA \\
\hline $\begin{array}{l}\text { 1. Procedimentos didáticos metodológicos } \\
\text { ensinar a Capoeira na escola }\end{array}$ & $\begin{array}{l}2,3,7,8,9,11,12,13,14,15,16, \\
17\end{array}$ & 14 \\
\hline 2. Conhecimentos sobre Capoeira Angola & 1 & 1 \\
\hline 3. Inserção da Capoeira nas aulas & 5 & 2 \\
\hline 4. Forma de inserção social & 6 & 1 \\
\hline 5. Mais experiência & 4,10 & 2 \\
\hline 6. Vivência prática da Capoeira & 18 & 1 \\
\hline
\end{tabular}

Fonte: Elaborada pelas autoras, 2017.

A maioria das respostas (14) menciona que as aulas colaboraram em apresentar procedimentos metodológicos e didáticos para se trabalhar com a Capoeira na escola. Essa constatação também se refletiu nos planos de aulas desenvolvidos pelos estudantes ao final da disciplina. De uma forma geral, os planos continham propostas variadas, tanto de conteúdos como de estratégias e metodologias. Grande parte delas foi proposta pela professora, ou seja, poucos foram além do que haviam aprendido nas aulas e buscaram outras brincadeiras ou metodologias.

De acordo com Figueiredo (2004), os estudantes, quando iniciam o curso de formação em EF, trazem suas experiências sociocorporais. Nesse campo, muitas dessas experiências estão relacionadas com as modalidades esportivas e, geralmente, elas ocorrem numa perspectiva tecnicista (FIGUEIREDO, 2004). Entretanto, a Capoeira é uma experiência nova, o que faz com que eles se remetam com mais frequência ao que foi ensinado nas aulas, 
pois, partindo da premissa da reprodução das experiências sociocorporais, torna-se muito mais cômoda a repetição do que a reflexão, a ação ou a reinvenção sobre o que lhes é ensinado.

Caparroz e Bracht afirmam:

[...] o professor não deve aplicar teoria na prática e, sim, (re)construir (reinventar) sua prática com referência em ações/experiências e em reflexões/teorias. É fundamental que essa apropriação de teorias se dê de forma autônoma e crítica, portanto, como ação de um sujeito, de um autor. (CAPARROZ; BRACHT, 2007, p. 27).

Assim, no caso desses futuros professores de EF, suscitar a curiosidade em aprender mais sobre o que vem sendo produzido em relação à Capoeira e às metodologias de ensino em $\mathrm{EF}$, bem como vivenciar mais a Capoeira, poderia gerar bons resultados.

Segundo Santos e Palhares (2010), é fundamental que os estudantes de EF tenham a oportunidade de conhecer e vivenciar a Capoeira, de modo que possam compreender como ela se organiza, além de se apropriar das dimensões de ensino-aprendizado que essa prática apresenta, aprofundando suas reflexões e reinventando seu ensino na escola.

Uma vez constatado o problema da reprodução do que lhes é ensinado na formação inicial, o estímulo para que esses estudantes se tornem docentes autônomos seria um caminho que poderia ser trilhado na superação da simples reprodução de suas experiências sociocorporais.

Sabemos que a formação inicial é apenas o primeiro passo de uma formação continuada na qual o docente deverá investir ao longo de sua vida profissional. Gadotti elucida que:

[...] a formação continuada do professor deve ser concebida como reflexão, pesquisa, ação, descoberta, organização, fundamentação, revisão e construção teórica e não como mera aprendizagem de novas técnicas, atualização em novas receitas pedagógicas ou aprendizagem das últimas inovações tecnológicas. (GADOTTI, 2003, p. 5).

Além das categorias mencionadas, é interessante tratar daquela que apresenta os conhecimentos sobre Capoeira Angola. Essa resposta, advinda do Aluno 1, que já tinha vivências na Capoeira e que participava de um grupo que trabalha com maior ênfase na modalidade de Capoeira Regional/Contemporânea, faz com que reflitamos acerca da importância de proporcionar aos discentes o acesso à diversidade de conhecimentos presentes nas diferentes modalidades de Capoeira. Isso faz com que as aulas de Capoeira na EF escolar não reproduzam as disputas existentes no mundo capoeirístico, no qual os diferentes grupos competem para provar qual das modalidades é melhor.

A terceira questão analisada foi: Qual o impacto que a oficina de Capoeira tem sobre a sua formação? Como você considera que ela contribuiu com sua formação? (Tabelas 5, 6, 7 e 8$)$. 
Tabela 5 - Unidades de contexto da primeira parte das respostas da questão 6: Qual impacto que a oficina de capoeira tem sobre a sua formação?

UNIDADES DE CONTEXTO

ALUNOS

FREQUÊNCIA

\begin{tabular}{lll}
\hline 1. Positivamente & A3, A5 & 2 \\
\hline 2. Grande & A14 & 1 \\
\hline 3. Importante & $\begin{array}{l}\text { A4, A7, A8, A9, A10, A12, } \\
\text { A13, A17 }\end{array}$ & 8 \\
\hline 4. Poderia ser maior, devido ao pouco tempo (30 horas) & A1 & 1
\end{tabular}

5. Não responderam diretamente, mas apontaram, aspectos positivos sobre como ela contribuiu
A2, A6, A11, A15, A16,

A18, A19, A20, A21

Fonte: Elaborada pelas autoras, 2017.

Tabela 6 - Categorias da primeira parte das respostas da questão 6 e suas respectivas unidades de contexto (Qual impacto a oficina de capoeira tem sobre a sua formação?)

\section{CATEGORIAS}

\begin{tabular}{llc}
\hline Impacto positivo & $1,2,3,5$ & 20 \\
\hline Impacto neutro (nem positivo e nem negativo) & 4 & 1
\end{tabular}

Fonte: Elaborada pelas autoras, 2017. 
Tabela 7 - Unidades de contexto da segunda parte das respostas da questão 6: Como você considera que ela contribuiu com sua formação?

UNIDADES DE CONTEXTO ALUNOS FREQUÊNCIA

\begin{tabular}{lll}
\hline 1. Ajudou no estágio & $\mathrm{A} 2, \mathrm{~A} 19$ & 2 \\
\hline 2. Conhecer a capoeira & $\begin{array}{l}\mathrm{A} 5, \mathrm{~A} 12, \mathrm{~A} 13, \mathrm{~A} 15, \\
\mathrm{~A} 16, \mathrm{~A} 21\end{array}$ & 6 \\
\hline
\end{tabular}

3. Inspiração para trabalhar com a capoeira na escola $\quad$ A2 1

\begin{tabular}{lll}
\hline 4. Possibilidade(s) de trabalhar com a capoeira na & $\mathrm{A} 5, \mathrm{~A} 7, \mathrm{~A} 10, \mathrm{~A} 11, \mathrm{~A} 17$ & 5
\end{tabular}
escola

5. Ajudando a pensar em como ensinar a capoeira na $\mathrm{A} 3$ escola

6. Ajudará a selecionar e promover os recursos A21 necessários (humanos e materiais) para o trabalho com a Capoeira na escola

\begin{tabular}{lll}
\hline 7. Primeiro contato & $\mathrm{A} 4, \mathrm{~A} 9, \mathrm{~A} 16$ & 3 \\
\hline 8. Vivências válidas & $\mathrm{A} 10, \mathrm{~A} 11$ & 2 \\
\hline 9. Apontou as possíveis dificuldades do meio escolar & $\mathrm{A} 7$ & 1
\end{tabular}

10. Pela Capoeira trazer elementos do processo cultural A6, A13, A14 e/ou histórico

11. Oportunidade de conhecer maneiras de utilizar o A8 1 conteúdo lutas nas escolas e nas aulas de EF

\begin{tabular}{lll}
\hline 12. Utilidade na carreira & $\mathrm{A} 13$ & 1 \\
\hline $\begin{array}{ll}\text { 13. Quebra de estereótipos } \\
\text { 14. Quebra de preconceitos religiosos }\end{array}$ & $\mathrm{A} 15$ & 1 \\
\hline $\begin{array}{l}\text { 15. Conhecimento de brincadeiras } \\
\begin{array}{l}\text { 16. Será o diferencial para tratar esse conteúdo na } \\
\text { escola }\end{array}\end{array}$ & $\mathrm{A} 1$ & 1 \\
\hline \begin{tabular}{l} 
17. Na formação \\
\hline
\end{tabular} & $\mathrm{A} 9, \mathrm{~A} 17, \mathrm{~A} 18, \mathrm{~A} 20$ & 1 \\
\hline
\end{tabular}

Fonte: Elaborada pelas autoras, 2017. 
Tabela 8 - Categorias da segunda parte das respostas da questão 6 e suas respectivas unidades de contexto (Como você considera que ela contribuiu com sua formação?)

\begin{tabular}{llc}
\hline \multicolumn{1}{c}{ CATEGORIAS } & \multicolumn{1}{c}{ UC } & FREQUENCIA \\
\hline $\begin{array}{l}\text { 1. Possibilidades de trabalhar com a capoeira na } \\
\text { escola }\end{array}$ & $3,4,5,6,11,16$ & 10 \\
\hline 2. Na carreira & $1,12,17$ & 7 \\
\hline 3. Conhecer a capoeira & 2 & 6 \\
\hline 4. Primeiro contato com a capoeira & 7 & 3 \\
\hline $\begin{array}{l}\text { 5. Porque a Capoeira traz elementos do processo } \\
\text { histórico }\end{array}$ & 10 & 3 \\
\hline 6. Rompimento de preconceitos & 13,14 & 2 \\
\hline 7. Vivências válidas & 8 & 2 \\
\hline 8. Apontou as dificuldades do meio escolar & 9 & 1 \\
\hline 9. Conhecimentode brincadeiras & 15 & 1 \\
\hline
\end{tabular}

Fonte: Elaborada pelas autoras, 2017.

Foi unanimidade a afirmativa de que o impacto da Oficina de Capoeira foi positivo na formação desses estudantes. As respostas reafirmam os dados que vêm sendo apresentados nesta análise. Como exemplo, citaremos abaixo algumas respostas que se referem ao impacto formativo dessa experiência:

\footnotetext{
- A oficina de Capoeira foi muito importante, pois eu nunca tinha experimentado essa prática corporal. Foi meu primeiro contato com ela. (ALUNO 4).

- A oficina de Capoeira foi muito importante para a minha formação, pois foi o meu primeiro contato com ela. Acredito que esta oficina será o diferencial quando eu for tratar esse conteúdo na escola. (ALUNO 9).
}

Vale destacar que, com as atividades desenvolvidas pela disciplina, alguns alunos já começaram a se apropriar do que foi aprendido, adaptando à sua realidade e iniciando o seu ensino. O Aluno 2 colocou em ação planos de ensino nas aulas de Estágio Supervisionado, o que demonstra a confiança adquirida com as aulas. O Aluno 7 afirmou que, a partir das vivências, poderia refletir acerca das possíveis dificuldades que encontraria quando fosse abordar esse tema na escola. Dentre elas, está a do preconceito religioso contra a prática da Capoeira. Estudos como os de Silva (2009), Mendonça (2013) e Barbosa (2013) apontam que sua prática é proibida para alunos filhos de adeptos de algumas religiões evangélicas. Consideramos essa questão bastante delicada, pois a Constituição Brasileira (BRASIL, 1988) preconiza o respeito de credo, mas assegura também o direito a uma educação laica.

O tema torna-se ainda mais complexo quando refletimos acerca da história da Capoeira e suas marcas culturais advindas dos descendentes africanos no Brasil. A Capoeira pode ser ensinada de forma laica na escola, mas não podemos descaracterizá-la suprimindo sua musicalidade, por exemplo, que a aproxima, em alguns aspectos, da musicalidade do candomblé, religião de origem africana.

Além disso, há outras manifestações da cultura corporal que podem ter uma ligação com outras religiões como a dança da quadrilha, que, na maioria das escolas, é ensinada nas aulas de EF e que tem sua origem nas festas dos santos católicos do mês de junho. Em consonância com nossos estudos, Rigoni (2013) e Barbosa (2013) constataram a proibição dos alunos adeptos a determinadas religiões evangélicas em participar de qualquer tipo de manifestação ligada a essas festas. 
$\mathrm{E}$, justamente pelo impacto crescente das religiões nas práticas das aulas de EF escolar, pela complexidade que esse tema apresenta e exige do campo científico, optamos por deixar esta reflexão iniciada neste artigo ecoando no leitor, e perspectivando desenvolvê-la numa próxima produção.

\section{Considerações finais}

A partir desta pesquisa, foi possível constatar que a maioria dos alunos reconheceu a importância da Capoeira como um conteúdo relevante a ser ensinado na escola. Por meio do contato com essa manifestação cultural, eles puderam praticá-la e apreender o histórico e os valores que a regem.

Entretanto, pensamos que essa experiência curricular poderia ser complementada por outras, como a participação em projetos de extensão e pesquisa relacionados com o tema (SANTOS; PALHARES, 2010).

Notamos que, embora tenha sido feito um esforço para que os estudantes refletissem acerca do que lhes era ensinado, ainda faltaram elementos a serem abordados com vistas a criar autonomia para os futuros professores e estimular a criatividade para a elaboração de novas propostas de ensino desse conteúdo. Caparroz e Bracht (2007) e Gadotti (2003) são unânimes quando afirmam que, quanto à dinâmica do fazer-se docente, não existe uma receita pronta, mas sim contextos nos quais os educadores agem, refletem e se constroem.

O presente estudo demonstra a importância de a formação inicial oferecer um amplo leque de vivências ao futuro professor de EF. Nesse caso, tratamos da Capoeira, mas os demais conteúdos, como a ginástica, a dança e modalidades esportivas, também merecem atenção e um tratamento pautado na vivência-reflexão para que os discentes se sintam seguros com relação às suas futuras intervenções no âmbito escolar, ou seja, os conteúdos de ensino devem ter espaço no currículo de formação inicial para serem vividos, refletidos e reelaborados.

Nesse sentido, há muito o que ser estudado, compartilhado e construído no que se refere à inserção da Capoeira no currículo de Licenciatura em EF. Um dos desafios expostos nesta pesquisa e em outras (SILVA, 2009; MENDONÇA, 2013; BARBOSA, 2013) é vencer o preconceito com relação à Capoeira, que deve ser valorizada como uma manifestação que reflete as diferenças sociais e culturais do Brasil.

Por fim, é necessário e fundamental o trabalho interdisciplinar para a abordagem de alguns conteúdos na escola. O exemplo da Capoeira é ilustrativo. Vimos que o esforço do professor de EF é insuficiente no que se refere ao ensino da musicalidade. Além disso, talvez a história da Capoeira tornasse a aula de História mais interessante e viva. Ou seja, já passamos do tempo de superar o processo de ensino-aprendizado que trata dos conhecimentos de forma compartimentada e estanque.

Esperamos que este texto possa suscitar novas reflexões sobre o tema e gerar novas propostas e abordagens.

\section{Referências}

ARAÚJO, R. C. Iê, viva meu mestre: a Capoeira Angola da Escola Pastiniana como práxis educativa. 2004. 236f. Tese (Doutorado em Educação) - Faculdade de Educação, Universidade de São Paulo, São Paulo, 2004. 
BAHIA. Secretaria da Educação. Orientações curriculares para o ensino médio área: linguagens/Secretaria da Educação. Salvador: Secretaria da Educação, 2015. 60 p. Disponível em: 〈http://escolas.educacao.ba.gov.br/orientacoescurricularesestaduais>. Acesso em: 22 jul. 2017

BAHIA. Secretaria da Educação. Superintendência de Desenvolvimento da Educação Básica. Diretoria de Educação Básica. Orientações curriculares e subsídios didáticos para a organização do trabalho pedagógico no ensino fundamental de nove anos. Salvador: Secretaria da Educação, 2013. 177 p.

BARBOSA, R. F. A interdição do corpo nas aulas de Educação Física: um estudo sobre os confrontos religiosos. 2013. 108 f. Dissertação (Mestrado em Educação) - Instituto de Educação, Universidade Federal de Mato Grosso, Cuiabá, 2013.

BARDIN, L. Análise de conteúdo. Lisboa: Edições 70, 2011.

BRASIL. Base Nacional Comum Curricular. Brasília: Ministério da Educação, 2017. Disponível em: <http://basenacionalcomum.mec.gov.br/images/pdf/4.1.3_BNCC-Final_LGGEF.pdf >. Acesso em: 22 jul. 2017.

Ministério da Cultura. Inventário para registro e salvaguarda da Capoeira como patrimônio cultural do Brasil. (Dossiê). Brasília: Ministério da Cultura, 2007.

Lei $\mathbf{n}^{\circ}$ 10.639, de 9 de janeiro de 2003. Altera a Lei $n^{\circ}$ 9394/96 para incluir no currículo oficial da Rede de Ensino a obrigatoriedade da temática: "História e Cultura AfroBrasileira”. Brasília, 2003.

Ministério da Educação/Secretaria de Educação Básica. Orientações curriculares para o ensino médio: linguagens, códigos e suas tecnologias. Brasília: Ministério da Educação/Secretaria de Educação Básica, 2006. v.1.

Ministério da Educação. Parâmetros Curriculares Nacionais: Educação Física. Brasília: Ministério da Educação, 1997.

Constituição da República Federativa do Brasil, 1988.

CAPARROZ, F. E.; BRACHT, V. O tempo e o lugar de uma didática da Educação Física. Revista Brasileira de Ciências do Esporte, Campinas, v. 28, n. 2, p. 21-37, jan. 2007.

CAPOEIRA, N. Capoeira: os fundamentos da malícia. Rio de Janeiro: Record, 1992.

FALCÃO, J. L. C. O jogo da Capoeira em jogo e a construção da práxis capoeirana. 2004. 394 f. Tese (Doutorado em Educação) - Faculdade de Educação, Universidade Federal da Bahia, Salvador, 2004a.

Para além das metodologias prescritivas na Educação Física: a possibilidade da capoeira como complexo temático no currículo de formação profissional. Pensar a prática, Goiânia, v. 7, n. 2, p. 155-170, jul./dez. 2004b. 
FIGUEIREDO, Z. C. C. Formação docente em Educação Física: experiências sociais e relação com o saber. Revista Movimento, Porto Alegre, v. 10, n. 1, p. 89-111, jan./abr. 2004.

GADOTTI, M. Boniteza de um sonho: ensinar-e-aprender com sentido. São Paulo: Grubhas, 2003.

Disponível

em: $<$ http://smeduquedecaxias.rj.gov.br/nead/Biblioteca/Forma\%C3\%A7\%C3\%A3o\%20Continua da/Artigos\%20Diversos/BONITEZA\%20DE\%20UM\%20SONHO\%20Ensinar-eaprender\%20com\%20sentido\%20-\%20gadotti.pdf>. Acesso em: 20 ago. 2016.

GONÇALVES, N. P. da C. A epistemologia do ensino da Capoeira na Escola de Educação Física e Desportos da Universidade Federal do Rio de Janeiro. 1997. 173 f. Dissertação (Mestrado em Educação Física) - Curso de Educação Física, Universidade Federal do Rio de Janeiro, Rio de Janeiro, 1997.

MENDONÇA, G. P. A. Capoeira na escola: análise e reflexões acerca de sua legitimação nas aulas de Educação Física das escolas estaduais da DIREC 13 - Jequié-Bahia. 2013. 164 f. Dissertação (Mestrado em Educação Física) - Curso de Educação Física, Universidade São Judas Tadeu, São Paulo, 2013.

MOLINA, R. M. K. O enfoque teórico metodológico qualitativo e o estudo de caso: uma reflexão introdutória. In: MOLINA NETO, V.; TRIVIÑOS, A. N. S. (Org.). A pesquisa qualitativa na Educação Física: alternativas metodológicas. 3. ed. Porto Alegre: Salina, 2010. p. 101-112.

NEGRINE, A. Instrumentos de coleta de informações na pesquisa qualitativa. In: MOLINA NETO, V.; TRIVIÑOS, A. N. S. (Org.). A pesquisa qualitativa na Educação Física: alternativas metodológicas. 3.ed. Porto Alegre: Salina, 2010. p. 61-100.

PIRES, A. L. C. S. Movimentos da cultura afro-brasileira: a formação histórica da capoeira contemporânea (1890-1950). 2001. Tese (Doutorado em História) - Instituto de Filosofia e Ciências Sociais (IFCH), Universidade Estadual de Campinas, Campinas, 2001.

A capoeira no jogo das cores: criminalidade, cultura e racismo na cidade do Rio de Janeiro (1890-1937). 1996. 258 f. Dissertação (Mestrado em História) - Instituto de Filosofia e Ciências Sociais (IFCH), Universidade Estadual de Campinas, Campinas, 1996.

REIS, A. L. T. Brincando de Capoeira: recreação e lazer na escola. Brasília: Valcy, 1997a.

REIS, L. V. S. O mundo de pernas para o ar: a Capoeira no Brasil. São Paulo: Publisher Brasil, 1997b.

RIGONI, A. C. C. Corpos na escola: (des)compassos entre a Educação Física e a religião. 2013. 175f. Tese (Doutorado em Educação Física) - Universidade Estadual de Campinas, Campinas, São Paulo, 2013.

ROCHA, M. A. Capoeira: uma proposta para a educação física escolar. 1990. $75 f$. Monografia (Especialização em Educação Física Escolar) - Faculdade de Educação Física, Universidade Estadual de Campinas, Campinas, 1990. 
SANTOS, G. O.; PALHARES, L. R. A capoeira na formação docente de educação física. Pensar a prática, Goiânia, v. 13, n. 3, p. 1-14, set./dez. 2010.

SÃO PAULO. Proposta Curricular do Estado de São Paulo: Educação Física. São Paulo: SEE, 2008.

SILVA, G. O. Capoeira: do engenho à universidade. 2. ed. São Paulo: [s.n.], 1995.

SILVA, P. C. da C. O ensino-aprendizado da Capoeira nas aulas de educação física escolar. 2009. 261f. Tese (Doutorado em Educação) - Faculdade de Educação, Universidade Estadual de Campinas, Campinas, São Paulo, 2009.

A Educação Física na roda de Capoeira: entre a tradição e a globalização. 2002. 238f. Dissertação (Mestrado em Educação Física) - Faculdade de Educação Física, Universidade Estadual de Campinas, 2002.

SILVA, P. C. C. et al. O ensino-aprendizado da capoeira nas aulas de Educação Física - diferentes contextos, novas possibilidades. In: Capoeira: abordagens socioculturais e pedagógicas. 1 ed. Curitiba: Appris, 2015. v. 1, p. 104-126.

SOARES, C. et al. Metodologia do ensino de Educação Física. 2.ed. São Paulo: Cortez, 2012.

SOARES, C. E. L. A Capoeira escrava e outras tradições rebeldes no Rio de Janeiro (1808 - 1850). Campinas-SP: Editora da Unicamp, 2001.

UNIVERSIDADE FEDERAL DO ESPÍRITO SANTO (UFES). Centro de Educação Física e Desportos. Projeto pedagógico de curso de licenciatura em Educação Física. 2014. Vitória: UFES, 2014.

Recebido em: 09/02/2018

Revisado em: 03/05/2018

Aprovado em: 10/08/2018

Endereço para correspondência:

letpau@yahoo.com.br

Paula Cristina da Costa Silva

Centro de Educação Física e Desportos

Universidade Federal do Espírito Santo, Centro de Educação Física e Desportos.

Av. Fernando Ferrari, 514

Goiabeiras

29075910 - Vitória, ES - Brasil 